Content list available at ICONSMAT

Journal of Construction Materials

Journal homepage: www.iconsmat.com.au/publication
Article history:

Received 8 May 2021

Received in revised form

15 May 2021

Accepted 16 May 2021

Available online 16 May 2021

\title{
A mixed-methods approach to developing and evaluating an SME business support model for innovation in rural England
}

\author{
Steve Fish ${ }^{1}$, Chris Lambert ${ }^{2 *}$ \\ ${ }^{1}$ Director of Partnerships and Business Engagement for the Faculty of Science and Technology at Lancaster \\ University, UK \\ ${ }^{2}$ Programme Manager based within the Department of Engineering at Lancaster University, UK \\ *Corresponding author: E: c.g.lambert@lancaster.ac.uk
}

\begin{abstract}
Cumbria is a geo-political county in Northwest England within which the Lake District National Park, a UNESCO World Heritage site is located. Whilst the area has a formidable reputation for natural beauty and historic assets, the innovation ecosystem is described as 'patchy' for a number of reasons. The county is one of the largest in England by area and is sparsely populated. This paper describes the needs, development and delivery of an SME business-support programme funded by the European Regional Development Fund, Lancaster University and the University of Cumbria. The Cumbria Innovations Platform (CUSP) Project has been designed to respond to the nuanced needs of SMEs in this locale, whilst promoting the adoption of research and innovation. CUSP utilizes a funnel method to support rural businesses with access to university innovation intervention. CUSP has been built on a three-tier model: Communicate, Collaborate and Create. The paper describes this project in detail and presents results in terms of output indicators achieved, a beneficiary telephone survey and wider economic forecasts. From a pragmatic point-of-view, the paper provides experiences and reflections of those people who are delivering and evaluating knowledge exchange. The authors discuss some of the benefits, challenges and implications for both policy makers and practitioners. Finally, the paper aims to serve as an invitation to others who may consider adopting a similar method of university-industry collaboration in their own region.
\end{abstract}

DOI: 10.36756/JCM.v2.4.5 C2021 Institute of Construction Materials

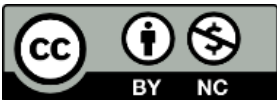

\section{Keyword}

Regional business support, rural business support, university-industry collaboration, collaborative R\&D, SMEs, knowledge exchange. 


\section{Introduction}

It has been well documented that universities can have a regional economic impact and as such can drive the knowledge-based economy (KBE) [1], [2]. A traditional technology transfer perspective focuses on intellectual property (IP) [3]; however, universities have the potential to offer a broader scope of engagement within their region [4] that includes student placements, retention of talent, the development of research and innovation projects that benefit individual companies or a region as well as technical support directed towards a specific business need.

One of the main challenges when developing productive interactions between universities and small to medium-sized enterprises (SMEs) is a range of differing and sometimes conflicting priorities and organisational cultures [5]. Whilst individuals employed in research-intensive universities have a priority to publish in high impact journals, those employed by SMEs often require relatively short-term technical support directed to improving business performance that may provide little or no opportunity to publish. An added level of complexity is the alignment of the capability within an academic institution to the requirements of SMEs in the region. Thus, a university might be well-placed to support an SME's technical request, or, the priorities of the two stakeholders could be divergent leading to a limited opportunity for interaction and by extension innovation.

The county of Cumbria is home to one of the best known and most visited national parks in the UK, the Lake District, however its innovation ecosystem is described as 'patchy' for a number of reasons. These include innovation assets existing within a single sector (nuclear) and its supply chains; corporate ownership of businesses outside of the region and an emphasis of innovation assets existing amongst larger enterprises [6]. These features result in businesses, particularly SMEs being less likely than in many other locations to be able to tap into a local network of innovators [6]. Additionally, Cumbria is the third largest county in England with a population density of 74 people per square kilometre compared to an average density in England of 407 people per square kilometre [7].

Even in the best-case scenario where 'push and pull' are complimentary, difficulties may compound the interaction because an SME's technical challenge cannot be directly communicated with the appropriate academic or knowledge exchange professional who is best able to provide advice and support. These were some of the considerations reviewed when designing the CUSP.

In March 2019 Cumbria published their Local Industrial Strategy [6]; within this document a number of priorities were identified:

$\begin{array}{ll}\text { - } & \text { Promoting Cumbria } \\ \text { - } & \text { Innovation and Idea } \\ \text { - } & \text { People and Skills } \\ \text { - } & \text { Insiness Environment } \\ \text { - } & \text { Places }\end{array}$

This document is predated by the Cumbria Rural and Visitor Economy Growth Plan 2017 [8], and common themes can be identified, including Innovation and Businesses, serving to highlight the regional significance of these priorities by policy makers. It is these two key pillars of regional business support that CUSP was built on.

In addition to aligning university 'push' and SME 'pull' was the additional constraint of Cumbria's geography, as alluded to earlier with the county covering an area of $6768 \mathrm{~km} 2$. CUSP's novel design aims to be cognisant of the demands of all the relevant stakeholders and to ultimately deliver innovative solutions to SMEs based in the rural county of Cumbria. European Regional Development Funding 
(ERDF) is used by EU member states to help promote and therefore level economic differences between and within member states. Funding was applied for via the UK's state secretariat, the Ministry of Housing, Communities and Local Government and following the application process was successfully awarded, to commence from late 2016. ERDF will typically fund up to $60 \%$ of the total cost of a project and in the case of CUSP, this was $f 4.083 \mathrm{M}$ (ERDF contribution of $f 2.45 \mathrm{M}$ ), with the remaining contribution being committed from the partners: Lancaster University and the University of Cumbria.

The aims of CUSP are to:

- $\quad$ Provide a range of innovation support to beneficiaries by accelerating interaction between SMEs and university partners;

- $\quad$ Deliver economic impact;

- Draw together a range of business support delivery units from different discipline areas and institutions to provide a clear, agile and inclusive means for companies to engage;

- Highlight the range of available knowledge exchange mechanisms for businesses, including those which are fully-funded and part-funded;

- $\quad$ Collaborate with SMEs using a distinctive innovation journey method.

These aims were dovetailed with the nuanced geography and innovation challenges described above as the authors aimed to provide a business support programme which was tailored to the needs of the SMEs in the region. It was therefore our aim to have maximum impact in the design of the approach. The means by which these aims were achieved is described in the following section: methodology.

\section{Methodology}

In many instances SMEs struggle to interact with universities due to their size and the broad offering in terms of technical capability, as well as other barriers discussed earlier. Navigating this complexity can often discourage SMEs from investigating the types of provision that a university can provide. Recognising these challenges, CUSP was designed from an SME centric standpoint with the aim of simplifying the interaction between university partners and external SME stakeholders. The aim of CUSP is to accelerate the identification of the SME innovation challenge and then provide the appropriate support that will contribute to improved business performance. This is achieved by using an innovation funnel model (Fig. 1) where SMEs are provided with access to different levels of appropriate support intensity, dependent on individual business requirements. Whilst the funnel model indicates that businesses will enter at the top and exit at the bottom, this is not exclusive, and flexibility is afforded in the model that enables a range of entry and exit points. The tailoring of the business support is done with knowledge exchange staff who help to facilitate and navigate appropriate intervention. The model is described in further detail below.

\section{Tier One: Communicate (Light-Touch Recruitment Activity)}

The initial phase focuses on awareness raising via workshops, including highlighting the capabilities and facilities that Cumbria's SMEs could get access to and benefit from, a form of 'shop window'. These sessions form the initial gateway in helping SMEs navigate the innovation support landscape in the county, including wider relevant organisations and programmes beyond the project partners. The recruitment events typically provide 3-6 hours support for an SME and act as a mechanism to encourage deeper collaborations between Cumbria's businesses and Lancaster University and University of Cumbria partners. 


\section{Tier Two: Collaborate (Strategic/Specialist Support)}

A series of activities provide more in-depth specialist support drawing upon the university partners capabilities. This support is focused on a six-month Innovation Development Programme, facilitated by Lancaster University Management School, during which participants will experience the following:

1. Workshops taking the Innovation Open Space approach utilising peer-to-peer learning around SMART specialisation priority sectors.

2. Workshops, based on SME demand, including identification and concept development, market feasibility, evidence assessment, readiness for market and market evaluation topics.

3. The creation of a network of cross-sectoral firms, with priority given to those in key growth sectors and their associated supply chains.

4. Establish Deep Trust Networks (DTNs) in Cumbria where business can talk to business.

5. Develop a trusted environment amongst participants to enable peer-to-peer learning, commencing with an initial overnight experiential that accelerates trust across the DTN.

\section{Tier Three: Create (Technical Development/Innovation Activities)}

The Create phase is the most time-intensive and focuses on specific SME need and the technical support required to introduce new products, processes or services. Highly specialised technical support is provided with the aim of maximising SMEs' opportunity to develop a new product, process or service. By doing so the intention is to drive the practical implementation of innovation in Cumbria.

The exact nature of the technical support required emerges as a result of an SME's exposure to the CUSP initiative. The mechanisms used for these longer collaborations between SMEs and the university partners include:

- $\quad$ Student summer interns (4-12 weeks)

- Masters student placements (4-12 weeks)

- $\quad$ Support from technical staff within the CUSP team (up to 12 weeks)

- Industrially focused PhDs (3 years) 


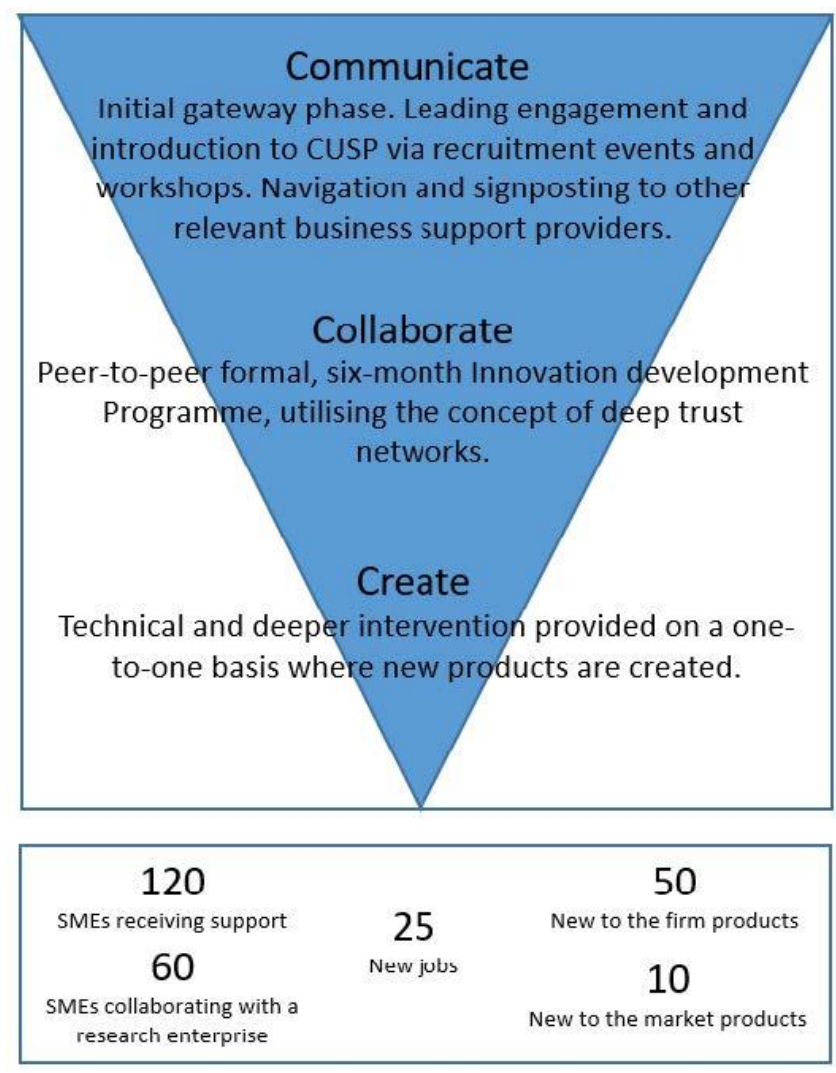
Figure 1 - Model depicting the communicate-collaborate-create model as an innovation funnel and the total
contracted target outputs.

The discipline areas of these tier three interactions are within science and technology departments: Computing and Communications, Chemistry, Engineering and Physics. Within each of these, technical staff provide one-to-one innovation support that may further utilise specialist facilities in those departments to help realise new products. This includes conducting research and development which may manifest itself in conducting design, prototyping, fabrication and testing. Much of the work provided in these technical areas is aimed to progress a product through maturity, by taking it through one or more technology readiness levels.

In addition to simplifying the interaction between an SME and a university partner, CUSP was designed to provide flexibility and access to a broad base of university-based expertise. Key performance indicators (KPIs) were agreed with the funding secretariat as part of the contractual obligations of receiving and using ERDF funding; these chiefly comprised enterprises supported ( $n=120)$, enterprises co-operating with a research entity $(n=60)$, firms assisted to introduce new to the firm products $(n=$ $50)$, firms assisted to introduce new to the market products $(n=10)$ and new jobs created $(n=25)$. For the avoidance of doubt and in-line with eligibility regulations, all beneficiaries met the definition criteria of SME. These contractual targets provide an on-going measure of project success although as proposed elsewhere, traditional innovation metrics within companies possess limitations and can therefore benefit from adopting a wider view of success [9]. 


\section{Results}

\section{Output Indicators}

ERDF projects typically have the requirement to generate outputs that deliver varying types of economic, environmental and social impact to a specific geographical area and aligned to national or state-level priorities. In this case, the former was to Cumbria and the latter to promoting research and innovation. The outputs that CUSP was tasked to deliver included (the code refers to national output guidance definitions):

- $\quad$ C01 - Number of enterprises receiving support;

- $\quad$ C04 - Number of enterprises receiving non-financial support;

- $\quad$ C08-Employment increase in supported enterprises;

- $\quad$ C26 - Number of enterprises cooperating with research entities;

- $\quad$ C28 - Number of enterprises supported to introduce new products to the market;

- $\quad$ C29-Number of enterprises supported to introduce new to the firm products.

The performance of the project as measured by outputs achieved versus outputs targeted is shown in Table 1.

Table 1 - Contracted ERDF output targets against achieved (N) and as a \%age, 34 months after start date.

\begin{tabular}{cccc}
\hline \hline Output & Target & Achieved & \% of target achieved \\
\hline C01 & 97 & 104 & 107 \\
C04 & 97 & 104 & 107 \\
C08 & 7 & 4.5 & 64 \\
C26 & 32 & 29 & 91 \\
C28 & 9 & 10 & 111 \\
C29 & 30 & 21 & 70 \\
\hline \hline
\end{tabular}

As seen from Table 1, most indicators are performing well and close to the conventionally accepted $10 \%$ leeway some commentators frequently use to monitor progress. There are two exceptions to this, which is C08 (employment increase in supported organisations) and C29 (number of enterprises supported to introduce new to the firm products). The principal reason for reported underperformance in these two KPIs is based on the juxtaposition of having a funding body requirement to report progress within the timeframes of the project and the time lag that exists between providing intervention and realizing impactful outputs. Assistance that helps a firm to create jobs or to introduce a new product will often be characterised by 'deep', prolonged and complex collaboration; this will hence often cause a delay in realizing economic potential. The challenges associated with these perceived conflicts of stakeholders are attended to in the discussion section below.

\section{Wider Impacts}

The outputs above have been analysed in terms of the broader reaching economic impact and was done in this instance by utilising the services of an economic impact evaluation provider. In order to undertake this estimation, the impact needed to reflect the net impact rather than gross impact. To achieve this the factors defined in Table 2 were used. 
Table 2 - Description of factors used in the calculation of wider economic impacts in the context of CUSP

\begin{tabular}{ll}
\hline \hline Factor & Explanation \\
\hline Deadweight & $\begin{array}{l}\text { What proportion of impacts would have happened without the } \\
\text { projects ever occurring }\end{array}$ \\
Displacement & $\begin{array}{l}\text { The proportion of impacts accounted for by reduced } \\
\text { outputs/outcomes elsewhere in the target area. }\end{array}$ \\
Substitution & $\begin{array}{l}\text { Whether a firm has substituted one activity for a similar one to take } \\
\text { advantage of public sector assistance. } \\
\text { Leakage }\end{array}$ \\
Multiplier effects & $\begin{array}{l}\text { Further economic activity associated with additional local income, } \\
\text { local supplier purchases and longer-term effects. }\end{array}$ \\
\hline \hline
\end{tabular}

Using the factors described above, extrapolation can occur to provide an estimated region-level of gross value added which helps to understand the wider impact of state intervention within the parameters associated to Cumbria and investment in innovation in research. The calculation is outlined in Table 3 and shows that the net additional contribution to the Cumbrian economy from CUSP is $£ 36.5 \mathrm{M}$.

Table 3 - Estimated GVA (Gross and Net) for Cumbria, arising from CUSP

\begin{tabular}{|c|c|c|}
\hline Factor & Measure & Adjustment \\
\hline Gross impact & $£ 84,359,423$ & $\begin{array}{l}\text { Cumbria economy-wide average GVA per FTE } 2017 \\
\text { applied to employment impacts, persisting for three } \\
\text { years; }\end{array}$ \\
\hline $\begin{array}{l}\text { Deadweight / } \\
\text { reference case }\end{array}$ & $£ 44,541,775$ & $\begin{array}{l}\text { 47\% - Mean sub-regional benchmark for business } \\
\text { development \& competitiveness, HCA Additionality } \\
\text { Guidance 2015; }\end{array}$ \\
\hline $\begin{array}{l}\text { Displacement / } \\
\text { Substitution }\end{array}$ & $£ 34,888,013$ & $\begin{array}{l}\text { 21\% - Mean sub-regional benchmark for business } \\
\text { development \& competitiveness, HCA Additionality } \\
\text { Guidance } 2015\end{array}$ \\
\hline Leakage & $£ 29,201,267$ & $\begin{array}{l}\text { 16\% - Mean sub-regional benchmark for business } \\
\text { development \& competitiveness, HCA Additionality } \\
\text { Guidance } 2015\end{array}$ \\
\hline Net additional & $£ 36,501,584$ & $\begin{array}{l}\text { Multiplier: } 1.25 \text { - Mean sub-regional benchmark for } \\
\text { business development \& competitiveness, HCA } \\
\text { Additionality Guidance } 2015\end{array}$ \\
\hline
\end{tabular}




\section{Beneficiary Survey}

The hypothesis that CUSP is fit-for-purpose can be tested in several ways. The first is assessing performance based on capture of outputs from the project and secondly is the wider economic impacts; some of which were attended to in the previous section. The third is by eliciting direct feedback from a subset of SMEs supported by the programme. In order to provide insights into the experiences of participating SMEs (beneficiaries), a mid-term evaluation was undertaken during which 21 telephone interviews were conducted. These interviews were conducted by the independent economic evaluator referred to above and which therefore provides a degree of objectivity, by being removed from those undertaking delivery of the project.

Participants to the survey were asked to rate their level of satisfaction to different elements of initial CUSP engagement (Table 4); reason for motivation of participation in the programme (Table 5); mechanism of support most experienced by participants (Table 6); overall satisfaction rates with expertise, advice and support (Table 5); reported benefits achieved to date (Table VIII) and individual comments provided to the survey team (Table 4).

Table 4 - Views of telephone survey participants on early contact with the CUSP project

\begin{tabular}{lc}
\hline \hline Question regarding satisfaction of elements of CUSP engagement & $\begin{array}{l}\text { \%age satisfied or very } \\
\text { satisfied }\end{array}$ \\
\hline Quality of information about the available support & $95 \%$ \\
Clarity of the eligibility criteria for receiving support & $95 \%$ \\
Ease of the application process & $95 \%$ \\
$\begin{array}{l}\text { Length of time taken between initial inquiry to working with the } \\
\text { project }\end{array}$ & $95 \%$ \\
\hline \hline
\end{tabular}

Table 5 - Reasons proved by telephone survey participants for engaging with CUSPP (top three)

\begin{tabular}{lc}
\hline \hline Area of motivation for participants & \%age of response \\
\hline Business strategy/business growth & $67 \%$ \\
New products/process development & $57 \%$ \\
Leadership/management/commercial skills development & $52 \%$ \\
\hline \hline
\end{tabular}


Table 6 - Mechanisms of support most experienced by telephone survey participants (top three)

\begin{tabular}{lc}
\hline \hline Mechanism & \%age of response \\
\hline Workshops & $94 \%$ \\
Perr learning & $93 \%$ \\
One-to-one tailored support & $85 \%$ \\
\hline \hline
\end{tabular}

Table 7 - Overall satisfaction rates with expertise, advice and support given in the extend to which telephone survey participants agreed with the statements provided

\begin{tabular}{lc}
\hline \hline View & \%age who agree \\
\hline Overall, I am happy with the support provided by the project & $100 \%$ \\
I received/am receiving high quality advice & $100 \%$ \\
The delivery approaches are/were fit for purpose & $100 \%$ \\
The project has/will address all of my support requirements & $67 \%$ \\
\hline \hline
\end{tabular}

Table 8 - Reported benefits achieved to date by telephone survey participants (top five)

\begin{tabular}{lc}
\hline \hline Benefits archived to date & \%age who agree \\
\hline More likely to engage with the University on other projects & $63 \%$ \\
More likely to seek support through other routes & $50 \%$ \\
Improved business networks/collaboration & $47 \%$ \\
Enhanced business/technical skills & $42 \%$ \\
Sustained employment levels & $41 \%$ \\
\hline \hline
\end{tabular}

Tables 4-9 provide reassuring, albeit anecdotal feedback from beneficiaries that the programme is fitfor-purpose and delivering ongoing positive outcomes. Limitations exist within such surveys which the authors acknowledge and whilst such shortcomings may be symptomatic of the method, it is hoped that the insights provided are better than having no data at all. 


\section{Comments}

"I now have an awareness of business models, advice from facilitators and have an open network of peers."

"It was absolutely great! It allowed me to take time out of my business to think and to be creative, away from a very hectic working environment."

"The input from peers was invaluable. The academic \& university input was very good. Exposure to other businesses opened up ideas I had not considered. However, post project support was unsatisfactory, there was no follow up, we were advised there would be a social meeting with our peer groups in the autumn (the course finished in April) but this never happened."

"Enhanced networking provided good contacts. I would like it noted that I did not think the course was long enough."

The outputs achieved by the project and the direct feedback from the SMEs indicate that CUSP'S operational model is robust, applicable to a broad range of market sectors and most likely transferable to a wide range of knowledge exchange scenarios. Further discussion including implications for practitioners and challenges experienced are provided in the following section, Discussion.

\section{Discussion}

Shucksmith undertook a review of rural development approaches where two broad models where identified: top- down or bottom-up and networked development [10]. The first model (top-down or bottom-up) reflects the origins and ownership of an initiative(s), whereas the second advocates a more integrated and inclusive approach. From several perspectives CUSP operates in the networked development mode, the reasons for which are threefold.

Firstly, the target external audience is the SME community in Cumbria. A variety of mechanisms are used to facilitate engagement that include workshops (as in tier one, 'Communicate'); peer-to-peer learning (as in tier two, 'Collaborate'); student placements; Ph.D. studentships; and longer-term technical support (as in tier three, 'Create'). Secondly, alignment of technical capability is present in Lancaster University and the University of Cumbria with the emerging challenges identified from the engagement initiatives above. Thirdly, the initiative received support from both the Cumbria Local Enterprise Partnership (CLEP) and the ERDF Managing Authority, Ministry for Housing Communities and Local Government (MHCLG).

The challenge for CUSP was to converge the stakeholders above and from this identify, then distil innovation-focused initiatives that provide economic and ultimately social impact in the region of Cumbria. The authors believe this has been achieved along with the aims outlined in the introduction section above by developing and implementing the Communicate-Collaborate-Create innovation model of business support in rural geographies. The benefits above combined with our model ensure that interaction between 
SMEs and university partners is simplified. Knowledge exchange staff at both universities help SMEs navigate the complexities of the partner universities. This removes one of the major deterrents to SMEs engaging with universities i.e. finding the right people to work with. Furthermore, the innovation funnel model deployed in CUSP has delivered a number of benefits. First is the provision of bespoke assistance from light-touch workshops to in-depth technical support. Secondly, it allows SMEs a flexible approach to innovation and time to assimilate the variety of expertise on offer by the university partners. Thirdly, it targets support where the need is greatest rather than progressing all the SMEs through the same programme. Inclusivity and therefore a broad appeal across different market sectors was also a factor considered before initiating the project. The expansive capability provided in CUSP was assembled to maximise the potential impact and to prevent limitation by Cumbria's geography and the accompanying clustering of SME based expertise.

Further ERDF projects built on the learning are acquired from CUSP. These include projects focusing on cyber security, digital health, smart materials and chemistry. Whilst some of these are at a very early stage, the indicators from the more mature initiatives is that our model of Communicate, Collaborate, Create is not only applicable within a rural context, but is equally pertinent across diverse disciplines.

\section{Challenges}

The co-ordination and delivery of a multi-disciplinary project such as CUSP have a variety of associated challenges. From the perspective of the university partners this was arguably the most complex knowledge exchange project of its type and a new way of working. Whilst many operational necessities were anticipated during the inception of CUSP the quote from Helmuth von Moltke is most apt: 'No battle plan survives contact with the enemy' [11]. In this context it means that upon contact with external stakeholders our delivery needed to be flexible and adapt accordingly.

CUSP's operational model was designed with a series of interdependencies, not only between the two university partners, but also between different departments. This was necessary to ensure our model of Communicate-Collaborate- Create operated efficiently and delivered maximum impact. With a project of this size and complexity failure points quickly become 'rate limiting steps.' These can be minimised by considering the following:

- The lead partner, in consultation with other partners should ensure that areas of responsibility are clearly defined and agreed prior to operational delivery. This is particularly important where areas of specialisation have been coalesced to provide an integrated support package for SMEs.

- Related to the point above is the requirement for individuals to understand where their role fits within the broader context of the initiative. It is easy to undertake productive activity without appreciating the fit within the broader aims of the initiative. Here a clear and coherent communication strategy assists SMEs to understand the resources they can access whilst also reinforcing project wide aims and specific responsibilities to university delivery teams.

- Establishing trust between the delivery teams and how this leads to knowledge sharing is critical. Where SMEs are being supported by multiple teams within a single project, it is essential those interactions are shared for the benefit of the stakeholders.

In addition, funding bodies need to appreciate that project plans will change over time and that a level of appropriate financial flexibility will assist delivery teams to be agile whilst minimising the administrative burden. Often associated with this is inconsistency linked to the interpretation of project outputs. Reclassification during the course of a project can frustrate delivery staff and SME beneficiaries who see this as an administrative burden. Defining and then adhering to the agreed requirements 
associated with a specified output at the beginning of a project should become 'best practice' for similar knowledge exchange initiatives.

\section{Wider implications for practitioners and policy makers}

Whilst much of the discussion has hitherto focused on the benefits and consequences of regional innovation business support to participating SMEs, it is important to consider how such activity affects universities. Notwithstanding the resource implications that large-scale knowledge exchange initiatives have on departments and faculties, university managers must seek assurances that these investments provide meaningful returns. The impact agenda has received increased prominence amongst HEls [11] as the need to demonstrate what happens to research is featured more prominently in the agendas of universities. This is evident through the increased value apportioned through, for example the UK government's periodic research quality exercise: Research Excellence Framework, in which research outputs are assessed alongside impact and environment. Research impact is multimodal [12] and capturing variations of this in its widest forms will be an important way in which universities are able to make clear the positive difference they can make. The impact agenda is complex and is not concerned solely with how research is applied or adopted for commercial exploitation, but also considers the role of universities in collaborating with SMEs on their innovation challenges. A consequence of business support projects such as CUSP is that universities are incrementally and organically pursuing an impact agenda different from those traditionally exploited. Emerging policy at this time in the UK is producing a knowledge exchange framework (KEF), a sister exercise to the already discussed REF and for education, the Teaching Excellence Framework (TEF). The KEF is undergoing pilot rollout following periods of development and consultation and whilst there is some uncertainty about the types of data that will be collected and how they will be collected, we can be sure that KEF will in some way drive funding. It is therefore important that universities consider how SME support programmes can help to contribute to metrics associated with these assessments. It is of course of equal importance that these metrics do not drive collaboration; the best and most innovative partnerships will result in impact and that should be captured by whichever means is appropriate in the context of national assessments.

In the ' $3-\mathrm{C}$ ' model described here, we believe CUSP is also producing a fourth ' $\mathrm{C}$ ', which is emerging after the programme has been in place for some three and-a-half years: Community. One of the perpetual problems of project-based funded support is how to create a lasting legacy; we hope by working with a network of SMEs that have shared common purpose in business improvement and are passionate about Cumbria, we are slowly creating a community of innovators. It is our hope that this community of innovators will last beyond relatively short-scale, fully-funded interventions, to produce a sustainable network for the future precisely in the construction sector where innovation plays a crucial role in the long term success of small and medium sized businesses [13-20]. Innovations that are particularly environmental and drive economic value [20-36].

\section{Conclusion}

We have described from first-hand experience a model of business-university collaboration for supporting innovation in SMEs. Other individuals and teams may wish to consider applying parts of the CUSP model elsewhere, in their own locales. We have shown this model to work effectively in rural Northwest England, but we believe this could be applied to other places in which universities and SMEs have the mutual opportunity to communicate, collaborate and create. This paper is therefore not just a dissemination piece, but an invitation to consider how the benefits and experiences could be applied to other regions across the globe. 


\section{Acknowledgments}

The authors provide their utmost gratitude and recognition to all those colleagues that have been involved with the administration, delivery and management of CUSP, the success of which has been determined by the spirit of individuals to collaborate by transcending traditional discipline boundaries. We gratefully acknowledge the funding body, the European Reginal Development Fund. Thanks are given to the support of the two partner institutions: Lancaster University and the University of Cumbria.

\section{References}

[1] Bercovitz, J. and Feldman, M., (2006). Entrepreneurial universities and technology transfer: A conceptual framework for understanding knowledge-based economic development. The Journal of Technology Transfer, 31(1), pp.175-188.

[2] Conceicao, P., Heitor, M.V. and Oliveira, P.M., (1998). Expectations for the university in the knowledge-based economy. Technological Forecasting and Social Change, 58(3), pp.203-214.

[3] Siegel, D.S., Veugelers, R. and Wright, M., (2007). Technology transfer offices and commercialization of university intellectual property: performance and policy implications. Oxford review of economic policy, 23(4), pp.640-660.

[4] Huggins, R. and Johnston, A., (2009). The economic and innovation contribution of universities: a regional perspective. Environment and Planning C: Government and Policy, 27(6), pp.10881106.

[5] Collier, A., Gray, B.J. and Ahn, M.J., (2011). Enablers and barriers to university and high technology SME partnerships. Small Enterprise Research, 18(1), pp.2-18.

[6] Cumbria Local Enterprise Partnership (2019). Cumbria's Local Industrial Strategy

[7] Office for National Statistics, (2018). Population estimates for the UK, England and Wales, Scotland and Northern Ireland: mid-2017.

[8] Cumbria Rural and Visitor Economy Growth Plan, (2017).

[9] Chesbrough, H., (2004). Managing open innovation. Research- Technology Management, 47(1), pp.23-26.

[10] Shucksmith, M., (2012). Future directions in rural development?. Dunfermline: Carnegie UK Trust.

[11] Universities, U.K., (2010). The future of research. London: Universities UK.

[12] Terämä, E., Smallman, M., Lock, S.J., Johnson, C. and Austwick, M.Z., (2016). Beyond academiaInterrogating research impact in the research excellence framework. PloS one, 11(12)

[13] R. Mezher and M. Hardie, "Case studies of traditional and innovative building approaches for aged care facilities," in Proceedings of the 43rd Australasian Universities Building Education Association (AUBEA) Conference: Built to Thrive: Creating Buildings and Cities that Support Individual Well-being and Community Prosperity, 6-8 November 2019, Noosa, QLD, Australia, 2019, pp. 144-159. 
[14] A. Y. Shaikh, R. Osei-Kyei, and M. Hardie, "A critical analysis of safety performance indicators in construction," International Journal of Building Pathology and Adaptation, 2020.

[15] K. Gunasekara, S. Perera, M. Hardie, and X. Jin, "An Exploratory Study to Identify Factors Affecting Performance of Construction Projects," in Constructing Smart Cities: Proceedings of the 22nd CIB World Building Congress (CIB2019), 17-21 June 2019, The Hong Kong Polytechnic University, Hong Kong, China, 2019.

[16] P. Molaei, L. Tang, and M. Hardie, "Measuring Walkability with Street Connectivity and Physical Activity: A Case Study in Iran," World, vol. 2, no. 1, pp. 49-61, 2021.

[17] M. Hardie, "Preparing Students for a Disruptive Construction Future," AUBEA, pp. 70-77, 2017.

[18] D. Chandler, M. Hardie, S. Perera, and C. Langston, "A proposed framework for measuring future construction industry performance," Accounting for Construction: Frameworks, Productivity, Cost and Performance, pp. 215-234, 2019.

[19] M. Hardie, "Technical innovation delivery in small and medium construction enterprises," 2011.

[20] L. Tang, M. Stevens, and M. Hardie, "Transforming design process in a "Giga" infrastructure project: case study in Australia," Built Environment Project and Asset Management, 2021.

[21] F. Sartipi, "Automatic sorting of recycled aggregate using image processing and object detection," Journal of Construction Materials, vol. 1, pp. 3-3, 2020, doi: https://doi.org/10.36756/JCM.v1.2.1.

[22] T. Boulos, F. Sartipi, and K. Khoshaba, "Bibliometric analysis on the status quo of robotics in construction," Journal of Construction Materials, vol. 1, pp. 2-3, 2020.

[23] F. Sartipi, "A brief critical view on the carbon-conditioning of recycled aggregate using pressure chamber," Journal of Construction Materials, vol. 2, pp. 1-4, 2020, doi: https://doi.org/10.36756/JCM.v2.1.4.

[24] F. Sartipi and A. Sartipi, "Brief review on advancements in construction additive manufacturing," Journal of Construction Materials, vol. 1, pp. 2-4, 2020, doi: https://doi.org/10.36756/JCM.v1.2.4

[25] A. Gharizadeh, F. Sartipi, E. Ayoubi, and A. Severino, "The chemical reactor design configuration of $\mathrm{CO} 2$ concrete green solution," Journal of Construction Materials, vol. 1, pp. 2-5, 2020, doi: https://doi.org/10.36756/JCM.v1.2.5.

[26] F. Sartipi, "Diffusion of Innovation Theory in the Realm of Environmental Construction," Journal of Construction Materials, vol. 1, pp. 4-2, 2020, doi: https://doi.org/10.36756/JCM.v1.3.2.

[27] F. Sartipi, "Dynamic data processing for building energy consumption," Journal of Construction Materials, vol. 2, no. 2021, pp. 2-4, 2020, doi: https://doi.org/10.36756/JCM.v2.2.4.

[28] F. Sartipi, A. Ghari Zadeh, and M. Gamil, "Electrical resistance of graphene reinforced cement paste," Journal of Construction Materials, 2019.

[29] V. Tam, F. Sartipi, and K. N. Le, "Gaps between supply and demand of recycled aggregate: Sydney metropolitan case study," Presented at the CRIOCM 2018, 2018. 
[30] F. Sartipi, "Influence of $5 \mathrm{G}$ and IoT in construction and demolition waste recycling-conceptual smart city design," Journal of Construction Materials, vol. 1, pp. 4-1, 2020, doi: https://doi.org/10.36756/JCM.v1.4.1.

[31] F. Sartipi, "Organizational structure of construction entities based on the cooperative game theory," Journal of Construction Materials, vol. 1, no. 2, 2020, doi: https://doi.org/10.36756/JCM.v1.3.3

[32] J. Luliano, A. Singh, and F. Sartipi, "Political-economical evaluation of CO2 capture in Australian building sector," Journal of Construction Materials, vol. 1, pp. 3-2, 2020, doi: https://doi.org/10.36756/JCM.v1.3.2.

[33] A. Kandiri, F. Sartipi, and M. Kioumarsi, "Predicting Compressive Strength of Concrete Containing Recycled Aggregate Using Modified ANN with Different Optimization Algorithms," Applied Sciences, vol. 11, no. 2, p. 485, 2021, doi: https://doi.org/10.3390/app11020485.

[34] F. Sartipi, "Preliminary structural design for extraterrestrial buildings," Journal of Construction Materials, vol. 2, pp. 2-3, 2021, doi: https://doi.org/10.36756/JCM.v2.2.3.

[35] F. Sartipi, "Publicizing construction firms by cryptocurrency," Journal of Construction Materials, vol. 2, pp. 3-1, 2021, doi: https://doi.org/10.36756/JCM.v2.3.1.

[36] F. Sartipi, K. Palaskar, A. Ergin, and U. Rajakaruna, "Viable construction technology for habitation on Mars: Fused Deposition Modelling," Journal of Construction Materials, vol. 1, no. 2, 2020, doi: https://doi.org/10.36756/JCM.v1.2.2. 